\title{
A POLÍTICA PÚBLICA DE INOVAÇÃO TECNOLÓGICA E A COOPERAÇÃO UNIVERSIDADE-EMPRESA: REVISITANDO A TEORIA DA AGÊECIA
}

\author{
THE TECHNOLOGICAL INNOVATION PUBLIC POLICY AND \\ UNIVERSITY-BUSINESS COOPERATION: REVISITING THE \\ AGENCY THEORY \\ Uinie Caminha ${ }^{1}$ \\ Caroline Viriato Memoria ${ }^{1}$
}

\section{Recebido em: 04/02/2018 Aceito em: 10/01/2018 \\ ucaminha@gmail.com carolinememoria@hotmail.com}

Resumo: A pesquisa baseou-se na premissa de que a existência de separação entre a propriedade e o controle do capital em cooperações tecnológicas universidade-empresa provoca o surgimento de conflitos de agência entre os participantes. Objetiva-se investigar se a Lei 11.196, de 21 de novembro de 2005, chamada de Lei do Bem, que fomenta inovação tecnológica no país, possui um sistema de incentivos suficientes para resolver os conflitos de agência existentes nas cooperações tecnológicas entre universidades e empresas. A análise bibliográfica possibilitou confirmar que nesse tipo de relação universidade-empresa, em regra, estão presentes elementos conceituais trabalhados pela Teoria da Agência. Dessa forma, as contribuições da Teoria da Agência são utilizadas para analisar a cooperação tecnológica incentivada pela Lei do Bem. Para o estudo, segue-se metodologia exploratória, analítica, empírica, argumentativa e propositiva. Verifica-se no trabalho que a Lei do Bem, com base na Teoria da Agência, não possui um sistema de incentivos capaz de alinhar os interesses entre universidade e empresa, haja vista que, para cooperação tecnológica universidade-empresa, a lei prevê incentivos para a empresa, mas não para a universidade. Dessa forma, a Lei do Bem deve ser repensada para incluir novas estruturas de incentivos com recompensas e controles para as partes das cooperações tecnológicas universidadeempresa.

Palavras-chave: Análise Econômica do Direito. Cooperação tecnológica universidadeempresa. Política pública de inovação tecnológica. Sistema de incentivos. Teoria da Agência.

\begin{abstract}
The research was based on the premise that the existence of a separation between ownership and control of capital in university-company technological cooperation causes the emergence of agency conflicts among the participants. The scope of this paper is to investigate whether Law 11.196, of November 21, 2005, called the Lei do Bem, which promotes technological innovation in the country, has sufficient incentives to solve existing agency conflicts in technological cooperation between universities and companies. The bibliographic analysis made it possible to confirm that in this type of university-company relationship, as a rule, there are conceptual elements worked on by the Agency Theory. Thus, the contributions of the Agency Theory are used to analyze the technological cooperation encouraged by the Lei do Bem. The study follows an exploratory, analytical, empirical, argumentative and propositive methodology. In conclusion, the Lei do Bem does not have an incentive system capable of aligning the interests between university and company. The law provides incentives for the company, but not for the university. The Lei do Bem must be rethought, therefore, to include new structures of incentives and controls between the parties of technological cooperation.
\end{abstract}

Keywords: Technological innovation public policy. University-company technological cooperation. System of incentives. Agency Theory. Law and Economics.

\footnotetext{
${ }^{1}$ Universidade de Fortaleza - UNIFOR- Fortaleza - Ceará - Brasil
} 


\section{INTRODUÇÃO}

O Brasil mantém políticas de apoio à inovação que têm resistido às mudanças no comando do Poder Executivo do país. Desde 2006, está em vigor a Lei 11.196, de 21 de novembro de 2005, que ficou conhecida como Lei do Bem, dentre outros motivos, por conceder incentivos na forma de renúncia fiscal para empresas inovadoras em atividades de pesquisa e desenvolvimento que operem em regime de tributação do lucro real.

A Lei do Bem, de acordo com a tendência internacional da inovação aberta (open innovation), permite a concessão de incentivos para que a empresa desenvolva atividades de inovação internamente ou com terceiros, sejam eles universidades, institutos de pesquisas, inventores independentes, microempresas ou empresas de pequeno porte. A cooperação universidade-empresa consiste num esforço coletivo para desenvolver novos conhecimentos tecnológicos para ampliação dos conhecimentos científicos e desenvolvimento e aprimoramento de novos produtos, processos e serviços.

A análise baseou-se na premissa de que, nesse tipo de cooperação tecnológica, como ambas as partes da relação são maximizadoras de utilidade, e há conflitos de interesses oriundo da assimetria de informações entre os participantes, surge a necessidade de mecanismos (sistema de incentivos) de controle das atividades do agente (universidade) que detém um nível mais alto de informações acerca da pesquisa contratada. Eis o objeto de análise da Teoria da Agência, que, para Jensen (1994) fornece a estrutura dentro da qual é possível modelar e compreender uma vasta gama de arranjos organizacionais humanos, de modo a reduzir as perdas que esses conflitos geram.

Logo, a atualidade do assunto, e a escassa produção científica fundamentam a escolha do tema para a construção de uma pesquisa que se fundamenta na aplicabilidade da teoria de agência a cooperações tecnológicas universidade-empresa. O estudo tem como objetivo investigar se a Lei do Bem, que fomenta inovação tecnológica no país por meio de cooperação tecnológica, possui incentivos suficientes para reduzir os conflitos de agência existentes nas cooperações entre universidades e empresas.

Nesse diapasão, a pesquisa é relevante, pois, num cenário pouco explorado, propõe a utilização de postulados da Economia ao Direito, ou seja, uma análise do fenômeno jurídico sob uma perspectiva econômica, pois a Análise Econômica do Direito pode favorecer a realização de cooperações tecnológicas mais eficientes e assim contribui para produção de conhecimento científico.

Desse modo, por meio de uma metodologia exploratória, analítica, empírica, argumentativa e propositiva, foi realizada pesquisa qualitativa, utilizando-se de levantamento bibliográfico em livros, periódicos, sítios eletrônicos, relatórios técnicos nacionais, relatórios de órgãos internacionais, leis e Constituição Federal, para construir o argumento necessário para responder ao seguinte questionamento: com base na Teoria da Agência, a Lei do Bem concede incentivos suficientes para alinhar os interesses existentes entre empresas e universidades numa cooperação tecnológica?

Revista do Direito [ISSN 1982-9957]. Santa Cruz do Sul, v. 3, n. 56, p. 3-16, set/dez. 2018. https://online.unisc.br/seer/index.php/direito/index 
Nessa perspectiva, de início é analisada a política pública de indução à inovação tecnológica, delineando-se a Lei do Bem e os tipos de relações entre atores da inovação que são beneficiadas pelos incentivos fiscais por ela regulados; em seguida, é apresentada a Análise Econômica do Direito, sobretudo a Teoria da Agência; e, por fim, analisa-se se a Lei do Bem possui incentivos que, nos termos da Teoria da Agência, alinhe os interesses existentes entre empresas e universidades na cooperação tecnológica.

Portanto, o artigo está assim estruturado: introdução, um capítulo sobre a política pública de inovação tecnológica da Lei do Bem, e outro sobre a aplicabilidade da Análise Econômica do Direito à cooperação tecnológica universidade-empresa e, por fim, a conclusão.

\section{A POLÍTICA PÚBLICA DE INOVAÇÃO TECNOLÓGICA DA LEI DO BEM}

Um dos primeiros a considerar a inovação tecnológica como imprescindível ao desenvolvimento econômico, Schumpeter trata o progresso tecnológico como resultado de atividades de pesquisa e desenvolvimento potencial e onerosa. Os recursos necessários para levar a cabo as atividades de pesquisa e desenvolvimento resultam do crescimento da população e do investimento em infraestrutura e em pesquisadores. A educação e a formação desses pesquisadores têm um papel especial na melhoria da capacidade que a economia tem para criar novas ideias. O processo de desenvolvimento econômico depende de incentivos que guiem o comportamento individual para inovação produtiva (DINIZ, 2010, p. 356-359).

O desenvolvimento científico, a pesquisa, a capacitação científica e tecnológica e a inovação são preocupações que a Constituição Federal de 1988 atribuiu ao Estado incentivar. Competindo também ao Estado dar tratamento prioritário à pesquisa científica básica e tecnológica e estimular a formação e o fortalecimento da inovação nas empresas (BRASIL, 1988).

Nesse contexto, desde 2006, está em execução no Brasil a política pública de incentivos à inovação tecnológica, com amparo jurídico na Lei no 11.196/2005 (Lei do Bem), regulamentada pelo Decreto $n^{\circ} 5.798$, de 7 de junho de 2006. Essa política tem como público alvo as empresas que fazem inovação tecnológica baseada em pesquisa e desenvolvimento - P\&D e que operam em regime de tributação do lucro real. A própria Lei do Bem (BRASIL, 2005) expressa o objetivo do Estado com essa política pública: incentivar melhorias incrementais em produtos e em processos, e efetivo ganho de qualidade ou produtividade, para que as empresas obtenham maior competitividade no mercado. Em 2016, o Código de Ciência, Tecnologia e Inovação (Lei n 13.243, de 11 de janeiro de 2016) entrou em vigor e ratificou os termos das legislações anteriores ao prever no art. $2^{\circ}$ os incentivos fiscais como instrumento de estímulo à inovação nas empresas (BRASIL, 2016).

Nesse diapasão, o Brasil está entre as 10 maiores economias do mundo no ranking do Fundo Monetário Internacional (IMF, 2016), no entanto, os dados mais recentes da inovação tecnológica ainda são pouco expressivos: 1.206 empresas inovadoras procuraram utilizar a Lei do Bem, fizeram investimentos da ordem de $R \$ 9,25$ bilhões e tiveram uma renúncia fiscal de cerca de $R \$ 1,68$ bilhões (BRASIL, 2014, p. 20).

Kannebley Júnior e Porto (2012, p. 51), na avaliação que fizeram da Lei do Bem, afirmam que se trata de uma política pública orientada ao mercado e de baixo custo administrativo, e que, ainda que seja de abrangência restrita às empresas de lucro real, principalmente as de grande porte, vem

Revista do Direito [ISSN 1982-9957]. Santa Cruz do Sul, v. 3, n. 56, p. 3-16, set/dez. 2018. https://online.unisc.br/seer/index.php/direito/index 
apresentando crescente interesse das firmas brasileiras. Segundo os autores, os resultados apresentados por meio de modelos econométricos são, no geral, positivos e significantes, porém pequenos, pois estimam que o impacto da Lei do Bem sobre o nível de dispêndios em P\&D das empresas beneficiadas seja, em média, de $7 \%$ a $11 \%$, ou seja, aumentam entre $7 \%$ e $11 \%$ os gastos com P\&D.

$\mathrm{Na}$ pesquisa qualitativa realizada por Avellar e Botelho (2016, p. 629) verificou-se que os montantes gastos em atividades de inovação tecnológica são superiores nas empresas que são apoiadas pela Lei do Bem. O estudo demonstrou também que as empresas beneficiadas possuem um percentual de pessoal ocupado com ensino superior completo acima da média das empresas não beneficiadas.

A Lei do Bem (BRASIL, 2005) descreve os incentivos fiscais concedidos na forma de renúncia fiscal:
Art. 17. (...)
I. dedução, para efeito de apuração do lucro líquido, de valor correspondente à soma dos dispêndios realizados no período de apuração com pesquisa tecnológica e desenvolvimento de inovação tecnológica classificáveis como despesas operacionais pela legislação do Imposto sobre a Renda da Pessoa Jurídica - IRPJ;
(...)
II. redução de $50 \%$ (cinqüenta por cento) do Imposto sobre Produtos Industrializados - IPI incidente sobre equipamentos, máquinas, aparelhos e instrumentos, bem como os acessórios sobressalentes e ferramentas que acompanhem esses bens, destinados à pesquisa e ao desenvolvimento tecnológico;
III. depreciação integral, no próprio ano da aquisição, de máquinas, equipamentos, aparelhos e instrumentos, novos, destinados à utilização nas atividades de pesquisa tecnológica e desenvolvimento de inovação tecnológica, para efeito de apuração do IRPJ e da CSLL;
IV. amortização acelerada, mediante dedução como custo ou despesa operacional, no período de apuração em que forem efetuados, dos dispêndios relativos à aquisição de bens intangíveis, vinculados exclusivamente às atividades de pesquisa tecnológica e desenvolvimento de inovação tecnológica, classificáveis no ativo diferido do beneficiário, para efeito de apuração do IRPJ;
$(\ldots)$
V. redução a 0 (zero) da alíquota do imposto de renda retido na fonte nas remessas efetuadas para o exterior destinadas ao registro e manutenção de marcas, patentes e cultivares.

Na prática, na determinação da base de cálculo da Contribuição Social sobre o Lucro Líquido - CSLL, os gastos que a empresa tiver com as contratações externas, bem como outros que estejam relacionados aos projetos de inovação tecnológica, poderão ser deduzidos adicionalmente para promover o aumento da despesa e assim diminuir o lucro tributável:

Art. 19. (...) a pessoa jurídica poderá excluir do lucro líquido, na determinação do lucro real e da base de cálculo da CSLL, o valor correspondente a até $60 \%$ (sessenta por cento) da soma dos dispêndios realizados no período de apuração com pesquisa tecnológica e desenvolvimento de inovação tecnológica, classificáveis como despesa pela legislação do IRPJ.

(...)

Revista do Direito [ISSN 1982-9957]. Santa Cruz do Sul, v. 3, n. 56, p. 3-16, set/dez. 2018. https://online.unisc.br/seer/index.php/direito/index 
$\S 1^{\circ}$. A exclusão de que trata o caput deste artigo poderá chegar a até $80 \%$ (oitenta por cento) dos dispêndios em função do número de empregados pesquisadores contratados pela pessoa jurídica.

$(\ldots)$

$\S 3^{\circ}$. (...) poderá excluir do lucro líquido, na determinação do lucro real e da base de cálculo da CSLL, o valor correspondente a até $20 \%$ (vinte por cento) da soma dos dispêndios ou pagamentos vinculados à pesquisa tecnológica e desenvolvimento de inovação tecnológica objeto de patente concedida ou cultivar registrado (BRASIL, 2005).

Os dispêndios e pagamentos relativos aos projetos incentivados deverão ser controlados contabilmente em contas específicas (BRASIL, 2005). Essa exigência legal obriga o empresário a manter uma organização interna com todos os gastos relacionados a projetos de pesquisa e desenvolvimento agrupados e separados das demais contas contábeis da empresa. É o que determina a Instrução Normativa $n^{\circ}$ 1.187, de 29 de agosto de 2011, da Receita Federal do Brasil (BRASIL, 2011):

Art. $3^{\circ}$ Para utilização dos incentivos de que trata esta Instrução Normativa, a pessoa jurídica deverá elaborar projeto de pesquisa tecnológica e desenvolvimento de inovação tecnológica, com controle analítico dos custos e despesas integrantes para cada projeto incentivado.

Parágrafo único. Na alocação de custos ao projeto de pesquisa tecnológica e desenvolvimento de inovação tecnológica de que trata o caput, a pessoa jurídica deverá utilizar critérios uniformes e consistentes ao longo do tempo, registrando de forma detalhada e individualizada os dispêndios, inclusive:

I - as horas dedicadas, trabalhos desenvolvidos e os custos respectivos de cada pesquisador por projeto incentivado;

II - as horas dedicadas, trabalhos desenvolvidos e os custos respectivos de cada funcionário de apoio técnico por projeto incentivado.

A utilização dos incentivos da Lei do Bem não está condicionada à aprovação prévia dos projetos de inovação pelo poder público federal, mas as empresas devem prestar informações após a utilização dos incentivos, como uma espécie de prestação de contas, o que faz com que algumas empresas contratem consultorias para realizar esse trabalho. Porém, esse tipo de custo operacional não é passível de incentivo fiscal pela Lei do Bem.

A inovação a que se refere essa lei é a inovação tecnológica, com aproximação conceitual de suas atividades com as previstas no Manual de Frascati² (OCDE, 2013). Os tipos de gastos e as atividades beneficiadas pela lei estão conceituados no decreto regulamentador:

\begin{abstract}
Art. $2^{\circ}$. (...)
I- inovação tecnológica: a concepção de novo produto ou processo de fabricação, bem como a agregação de novas funcionalidades ou características ao produto ou processo que implique em melhorias incrementais, e efetivo ganho de qualidade ou produtividade, resultando maior competitividade no mercado;

II- pesquisa tecnológica e desenvolvimento de inovação tecnológica, as atividades de:
\end{abstract}

\footnotetext{
2 O Manual de Frascati é um documento preparado e publicado pela Organização para a Cooperação e Desenvolvimento Econômico que propõe uma metodologia para levantamentos sobre pesquisa e desenvolvimento experimental e contém definições de pesquisa básica, pesquisa aplicada, pesquisa e desenvolvimento, pessoal de pesquisa: pesquisadores, técnicos, pessoal auxiliar (OCDE, 2013).
} 
a) pesquisa básica dirigida: os trabalhos executados com o objetivo de adquirir conhecimentos quanto à compreensão de novos fenômenos, com vistas ao desenvolvimento de produtos, processos ou sistemas inovadores;

b) pesquisa aplicada: os trabalhos executados com o objetivo de adquirir novos conhecimentos, com vistas ao desenvolvimento ou aprimoramento de produtos, processos e sistemas;

c) desenvolvimento experimental: os trabalhos sistemáticos delineados a partir de conhecimentos pré-existentes, visando a comprovação ou demonstração da viabilidade técnica ou funcional de novos produtos, processos, sistemas e serviços ou, ainda, um evidente aperfeiçoamento dos já produzidos ou estabelecidos;

d) tecnologia industrial básica: aquelas tais como a aferição e calibração de máquinas e equipamentos, o projeto e a confecção de instrumentos de medida específicos, a certificação de conformidade, inclusive os ensaios correspondentes, a normalização ou a documentação técnica gerada e o patenteamento do produto ou processo desenvolvido; e

e) serviços de apoio técnico: aqueles que sejam indispensáveis à implantação e à manutenção das instalações ou dos equipamentos destinados, exclusivamente, à execução de projetos de pesquisa, desenvolvimento ou inovação tecnológica, bem como à capacitação dos recursos humanos a eles dedicados;

III- pesquisador contratado: o pesquisador graduado, pós-graduado, tecnólogo ou técnico de nível médio, com relação formal de emprego com a pessoa jurídica que atue exclusivamente em atividades de pesquisa tecnológica e desenvolvimento de inovação tecnológica (BRASIL, 2006).

A utilização da Lei do Bem implica gastos relacionados à $P \& D$ que são incentivados e outros que não o são. A Instrução Normativa no 1.187, de 29 de agosto de 2011, da Receita Federal do Brasil, exemplifica alguns tipos de gastos beneficiados pela Lei do Bem:

Art. 5․ (...)

I - os salários e os encargos sociais e trabalhistas de pesquisadores e de pessoal de prestação de serviço de apoio técnico de que tratam a alínea "e" do inciso II e o inciso III do art. $2^{\circ}$;

II - a capacitação de pesquisadores e de pessoal de prestação de serviços de apoio técnico de que tratam a alínea "e" do inciso II e o inciso III do art. 2 .

$\S 1$ 1 Para fins deste artigo, poderão ser considerados como dispêndios os custos com pesquisadores contratados pela pessoa jurídica, sem dedicação exclusiva, desde que:

I - conste expressamente em seu contrato de trabalho o desempenho como pesquisador em atividades de inovação tecnológica desenvolvida pelo empregador;

II - a empresa possua, para o projeto incentivado, controle das atividades desenvolvidas e respectivas horas trabalhadas.

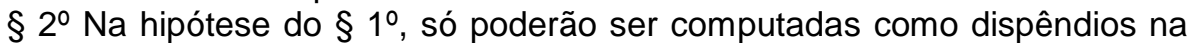
forma do caput do art. $4^{\circ}$ as horas efetivamente trabalhadas no projeto incentivado.

(...)

§ 4ำ Também são considerados dispêndios vinculados à pesquisa tecnológica e desenvolvimento de inovação tecnológica os gastos destinados ao registro e manutenção de marcas, patentes e cultivares, ainda que pagos no exterior.

Por meio da Lei do Bem, o Estado não incentiva apenas as atividades feitas internamente nas empresas, mas também a pesquisa tecnológica e desenvolvimento de inovação tecnológica 
contratados no país com universidade, instituição de pesquisa, microempresas, empresas de pequeno porte e inventor independente (BRASIL, 2005):

\begin{abstract}
Art. 17. (...)
$\S 2$ ㅇ disposto no inciso I do caput deste artigo aplica-se também aos dispêndios com pesquisa tecnológica e desenvolvimento de inovação tecnológica contratados no País com universidade, instituição de pesquisa ou inventor independente de que trata o inciso IX do art. $2^{\circ}$ da Lei $n^{\circ} 10.973$, de 2 de dezembro de 2004, desde que a pessoa jurídica que efetuou o dispêndio fique com a responsabilidade, o risco empresarial, a gestão e o controle da utilização dos resultados dos dispêndios.

(...)

Art. 18. Poderão ser deduzidas como despesas operacionais, na forma do inciso I do caput do art. 17 desta Lei e de seu § 60, as importâncias transferidas a microempresas e empresas de pequeno porte de que trata a Lei $n^{\circ} 9.841$, de 5 de outubro de 1999, destinadas à execução de pesquisa tecnológica e de desenvolvimento de inovação tecnológica de interesse e por conta e ordem da pessoa jurídica que promoveu a transferência, ainda que a pessoa jurídica recebedora dessas importâncias venha a ter participação no resultado econômico do produto resultante.
\end{abstract}

Essa cooperação tecnológica beneficiada pela Lei do Bem encontra respaldo teórico em Chesbrough (2003, p. 49-52), para quem a empresa que deseja avançar sua tecnologia em um mundo de conhecimento abundante o encontrará disponível fora da empresa para contratar, dispensando a necessidade de treinamento de pessoal interno e manutenção de empregos formais internamente. A lógica subjacente ao processo de inovação está agora completamente invertida: a empresa pode se concentrar numa área específica sem ter que fazer tudo. As empresas não devem guardar suas tecnologias, esperando até que seus próprios negócios façam uso delas. Isto não quer dizer que as empresas devam interromper todas as pesquisas internas até porque nem todo conhecimento externo se adaptará aos negócios da empresa. No entanto, qualquer pesquisa que seja feita internamente deve levar em conta a riqueza de atividade existente fora da empresa.

Dessa forma, o fluxo do conhecimento se dá, portanto, interna e externamente às empresas. A inovação aberta (open innovation) é um termo criado por Chesbrough (2003, p. 43) que significa que as idéias podem vir de dentro ou de fora da empresa e podem da mesma forma ir para o mercado. As universidades estão cheias de professores com profundo conhecimento e esses professores são cercados por alunos que juntamente com aqueles produzem ciência de maneira excelente e aplicável aos problemas empresariais. $\mathrm{O}$ avanço da pesquisa científica universitária e a distribuição dessa pesquisa significa que o conhecimento difundido leva novas idéias ao mercado (CHESBROUGH, 2003, p. 44-45).

A Lei do Bem concede incentivos para cooperações tecnológicas universidade-empresa, que, segundo ponderam Segatto-Mendes e Rocha (2005, p. 173), contêm dois componentes centrais: as empresas que atuam com o aporte financeiro e informações do setor produtivo e do mercado; e as universidades, que fornecem o conhecimento e estrutura de pesquisa do meio acadêmico. Desse modo, a Lei do Bem segue a abordagem da Hélice Tríplice, que, compreende a inovação como resultante de relações complexas e dinâmicas entre ciência, tecnologia, pesquisa e desenvolvimento na universidade, na empresa e no governo (ETZKOWITZ, 2000, p. 113).

Revista do Direito [ISSN 1982-9957]. Santa Cruz do Sul, v. 3, n. 56, p. 3-16, set/dez. 2018. https://online.unisc.br/seer/index.php/direito/index 
Sobre as cooperações tecnológicas universidade-empresa, Segatto-Mendes e Mendes (2006, p. 60) ponderam que:

A cooperação universidade-empresa não representa apenas o melhoramento tecnológico de produtos ou a criação de inovações; ela também significa uma troca de relacionamento em que a transferência do conhecimento entre as partes é muito importante, pois é por meio dessa transferência que ambas as partes poderão alcançar melhores resultados no processo de pesquisa. Por isso, a transferência do conhecimento deve ser estruturada e encorajada desde o início do programa de pesquisa para que uma comunicação frequente e aberta seja firmada entre os dois grupos.

Ribeiro e Galeski (2009, p. 79) entendem as políticas fiscais como mecanismos extrafiscais de correção de falhas de mercado e/ou como estratégias de desenvolvimento econômico regional:

A alocação mais eficiente dos recursos ocorre pelo livre funcionamento do mercado, e não pela intervenção do Estado. Apesar de o mercado ser o melhor local para se obter a eficiência alocativa ótima, não raro apresenta falhas. Somente na presença destas deve haver a intervenção estatal.

Nessa perspectiva, as cooperações tecnológicas universidade-empresa são acordos oficializados por instrumento contratual para desenvolvimento tecnológico de produtos e processos. Logo, o apoio governamental às atividades de P\&D visa, basicamente, a reduzir o custo relativo e/ou o risco associado a essas atividades. Porém, embora exista a expectativa de uma atuação conjunta das instituições participantes nesse tipo de cooperação, Segatto-Mendes e Rocha (2005, p. 172) constatam a existência de interesses divergentes, controle sobre resultados não-pecuniários e fontes de assimetria informacional, que revelam características da Teoria da Agência, cuja idéia fundamental, para Jensen (1994), é que as pessoas têm interesses próprios diferentes e cada uma busca maximizar seus próprios objetivos. Dessa forma, passa-se à análise da aplicabilidade da Teoria da Agência, às cooperações tecnológicas reguladas pela Lei do Bem.

\section{A APLICABILIDADE DA TEORIA DA AGÊNCIA À COOPERAÇÃO TECNOLÓGICA REGULADA PELA LEI DO BEM}

O movimento da Law and Economics (Análise Econômica do Direito - AED) teve início na Universidade de Chicago, na década de 60, com Ronald Coase e Richard Posner, e ficou conhecido como Escola de Chicago. A AED aborda a transformação e a reformulação da função do Direito, entendendo que o sistema jurídico constitui-se em instrumento que produz e reproduz uma racionalidade material do tipo econômico, porquanto Direito e mercado traduzem a mesma lógica, que é a da maximização da riqueza.

O artigo seminal de Ronald Coase intitulado "O problema do custo social" foi um marco no estudo da Análise Econômica do Direito, pois, ao tratar de um tema especificamente econômico, que é o custo social, elabora um pressuposto teórico chamado de "Teorema de Coase", segundo o qual se os direitos de propriedade sobre qualquer recurso forem definidos, e se os custos de transação a eles relacionados forem suficientemente baixos, a utilização final do recurso independe da concessão inicial desses direitos a uma das partes, embora a decisão dos juízes afete a distribuição da riqueza entre elas.

Revista do Direito [ISSN 1982-9957]. Santa Cruz do Sul, v. 3, n. 56, p. 3-16, set/dez. 2018. https://online.unisc.br/seer/index.php/direito/index 
O custo de transação é o elemento que a Escola de Chicago identifica como responsável pela incompletude dos contratos, podendo se apresentar em razão da racionalidade limitada das partes, principalmente quando os contraentes estão diante de decisões complexas, já que nem sempre os indivíduos possuirão todas as informações necessárias para se alcançar a decisão "ótima", bem como em virtude da assimetria de informação, da conduta oportunista, dentre outros fatores (CAMINHA; LIMA, 2014, p. 163). Coase (1960, p. 2) entende que os prejuízos são sempre de natureza recíproca, afirmando que a solução deve ser a que provoque o menor prejuízo, sendo irrelevante a investigação das causas.

Segundo Posner (2007, p. 24-26), distinguem-se duas vertentes da AED: a positiva e a normativa. A positiva explica, pelo método econômico, as normas jurídicas e suas consequências, elucidando porque certas normas são seguidas pela sociedade e outras não, como os agentes influenciados por determinada norma irão agir, os custos de efetivação de certas normas etc. A normativa - marca da Escola de Chicago e vertente mais conhecida da Análise Econômica do Direito - pela qual os juízes e legisladores devem estabelecer normas jurídicas que induzam um comportamento eficiente (economicamente ou não), sofreu certo abrandamento em obras mais recentes para ponderar que a eficiência é apenas mais um valor a ser perseguido pelo Direito, mas não o único ou o mais importante.

A todo instante, são feitas escolhas racionais acerca do que contratar, com quem contratar, quando contratar e como contratar um produto ou serviço, decidindo, sempre, da forma que nos ocasione um menor custo de oportunidade e maior utilidade possível:

O que pressupõe a análise econômica do Direito é que a conduta legal ou ilegal de uma pessoa é decidida a partir de seus interesses e dos incentivos que encontra para efetuá-la ou não. (...) A Economia estuda as escolhas, os custos, riscos e benefícios que os agentes econômicos (sujeitos de direito) encontram na busca pela maximização de seus próprios interesses. (PIMENTA, 2006, p. 29.)

Para maximizar o resultado de suas atividades, as organizações investem em projetos de inovação, e as decisões de investimento dessa natureza estão sujeitas à presença de custos específicos associados, irreversibilidade, restrições financeiras, assimetrias de informação e incertezas, por se dar o investimento em atividades baseadas em conhecimento e com riscos relacionados aos seus retornos (HALL, 2002, p. 4). "Muitas são as possibilidades de falhas de mercado, como, por exemplo, assimetria de informação, externalidades, displicência, ações culposas" (SZTAJN, 2004, p. 35).

A pesquisa teve como base a investigação de Segatto-Mendes e Rocha (2005, p. 172-174), que verificaram a existência de conflitos de interesses entre os participantes de cooperações tecnológicas universidade-empresa e concluíram pela possibilidade de aplicação de conceitos desenvolvidos na Teoria da Agência para o aperfeiçoamento desses arranjos de pesquisa cooperativa. Segundo esses autores, com a transferência de recursos das empresas para projetos de pesquisa na universidade, que passam a ser administrados pelos pesquisadores acadêmicos responsáveis, é possível observar as figuras do agente e do principal.

Revista do Direito [ISSN 1982-9957]. Santa Cruz do Sul, v. 3, n. 56, p. 3-16, set/dez. 2018. https://online.unisc.br/seer/index.php/direito/index 
Sempre que um indivíduo depende da ação de outro, um relacionamento de agência surge (PRATT e ZECKHAUSER, 1985, p. 2). As informações que o principal (empresa) recebe são fornecidas em sua maioria pelo agente (universidade), o que permite a este um controle do tipo e profundidade da informação fornecida àquele, surgindo a possibilidade da assimetria informacional, ou seja, de agente e principal possuírem diferentes níveis de informação.

Assimetria de informação é um conceito que lida com o estudo de decisões dos agentes econômicos em transações em que uma parte tem mais ou melhor informação do que a outra parte. Isso cria um desequilíbrio de poder nas transações que por vezes pode levar a problemas de alocação (PORTO, 2013, p. 33). Em se tratando das cooperações universidade-empresa, a assimetria informacional resulta do acesso diferenciado em que agente e principal têm às informações: o agente (universidade), por estar atuando diretamente no processo, possui um grau mais aprofundado de conhecimento sobre $o$ andamento das pesquisas.

Para a cooperação tecnológica universidade-empresa, são fornecidos recursos e equipamentos que serão gerenciados pelo pesquisador universitário responsável pelo objeto do contrato. Logo, nas pesquisas cooperativas, a separação entre a propriedade e o controle do capital leva ao surgimento de conflitos entre os participantes e cria a necessidade por parte do principal (empresa) de acompanhamento e monitoramento do agente (universidade) (SEGATTO-MENDES; ROCHA, 2005, p. 180).

Uma especificidade das cooperações universidade-empresa é a de que há clara diferenciação das funções e atividades de cada participante e essa peculiaridade refere-se às cooperações serem uma relação baseada no conceito de cooperação, isto é, existe a expectativa de uma atuação conjunta das instituições participantes (SEGATTO-MENDES; ROCHA, 2005, p. 181). Porém, na realidade, ambas as partes da relação são maximizadoras de utilidade e existe uma boa razão para acreditar que o agente não atuará sempre nos melhores interesses do principal (JENSEN e MECKLING, 1976, p. 308-309). Logo, "A cooperação universidade-empresa implica, desse modo, atuação conjunta de duas instituições de natureza distinta, em que conflitos podem ocorrer em função dos interesses divergentes" (SEGATTO-MENDES; ROCHA, 2005, p. 173).

Jensen e Meckling (1976, p. 308) definem uma relação de agência como "um contrato sob o qual uma ou mais pessoas (o(os) principal(is)) contratam outra pessoa (o agente) para desempenhar algum serviço em seu interesse o qual envolve delegação de alguma autoridade para tomada de decisão para o agente". Nesse contexto, Jensen (1996) afirma que essas relações de agência estão presentes sempre as interações envolverem esforços cooperativos.

No caso da cooperação tecnológica, Segatto-Mendes e Rocha (2005, p. 178) afirmam que existe assimetria informacional, pois:

(...) o agente, por estar atuando diretamente no processo, possui um grau mais aprofundado de conhecimento sobre 0 andamento das pesquisas, 0 que dificulta para a empresa a garantia de que seus interesses estejam sendo buscados em um esforço máximo, além de que é o próprio professorcoordenador quem fornece as informações para a empresa, portanto, ele pode controlar a quantidade e a qualidade da informação fornecida.

Esses autores também verificam, em estudo empírico sobre as contribuições da Teoria da Agência para a cooperação tecnológica universidade-empresa, que: 
(...) a exigência do sigilo ou de consentimento para publicação dos levantamentos realizados pela pesquisa e demonstram que questões como propriedade industrial, direitos de comercialização e sigilo representam pontos delicados do processo cooperativo e uma importante preocupação das empresas na preservação de seus interesses. Dessa forma, uma vez que as universidades têm uma preocupação maior com a difusão do conhecimento e com a ampliação da base científica nacional, essa abordagem representa um foco de divergência de interesses (SEGATTOMENDES E ROCHA, 2005, p. 180).

A Lei do Bem, ao prever a concessão de incentivos para cooperação tecnológica entre universidades e empresas, estabeleceu as seguintes condições para conceder os benefícios: a empresa que efetuar a despesa com a cooperação tecnológica deve ficar com a responsabilidade, o risco empresarial, a gestão e o controle da utilização dos resultados (BRASIL, 2006). Entretanto, segundo Cooter e Ulen (2010, p. 99), "essas condições estabelecidas pelo legislador são, muitas vezes, menos eficientes se comparadas com condições que decorrem de acordos entre as pessoas".

Por se tratar de uma cooperação, existe a expectativa de uma atuação conjunta da universidade e da empresa, porém a Lei do Bem já determina as regras da cooperação, o que reduz a livre negociação das cláusulas contratuais entre universidade e empresa, e propicia o acirramento do conflito de interesses pelos motivos apontados pelos autores citados. Desse modo, embora a Lei do Bem preveja que a autoridade para tomada de decisão seja da empresa, na prática, a universidade, por estar atuando diretamente na pesquisa, possui um grau mais aprofundado de conhecimento sobre o andamento das atividades, o que dificulta para a empresa a garantia de que seus interesses estejam sendo buscados em um esforço máximo. Além disso, a empresa tem o sigilo da pesquisa como prioridade, e a universidade se preocupa mais com a difusão do conhecimento.

Nesse diapasão, para reduzir esse conflito de interesses, Segatto-Mendes e Rocha (2005, p. 181) sugerem que os pesquisadores da universidade deveriam receber uma parcela do resultado geral que a empresa obterá, por acreditarem que isso fornecerá maior incentivo ao trabalho dos pesquisadores, reduzindo conflitos, pois estarão motivados a ir além dos objetivos básicos colocados no contrato. Inclusive esses recursos poderiam ser utilizados livremente pelo pesquisador em estudos de seu interesse, sem cerceamento ou inibição de sua atuação.

Logo, partindo da premissa de que a Teoria da Agência é aplicável à cooperação tecnológica entre universidade e empresa, a pesquisa verifica que a Lei do Bem não dispõe de um sistema de incentivos que motivem os pesquisadores das universidades (agentes) a alcançar o quanto antes os objetivos do contrato de cooperação e nem a ir além dos objetivos básicos colocados no contrato.

Portanto, sugere-se a revisão da Lei do Bem, pois, como ensina Jensen (1996), devem ser alteradas as estruturas institucionais, os contratos e arranjos informais para reduzir o conflito de interesses, para aumentar as chances de que os stakeholders tomem as melhores decisões possíveis, por meio da criação de incentivos suficientes para os encorajar a se moverem na direção correta. No entanto, o autor adverte que o dinheiro nem sempre é a melhor forma de motivar pessoas, o importante é que as partes possam compartilhar os ganhos.

Revista do Direito [ISSN 1982-9957]. Santa Cruz do Sul, v. 3, n. 56, p. 3-16, set/dez. 2018. https://online.unisc.br/seer/index.php/direito/index 


\section{CONSIDERAÇÕES FINAIS}

Cada vez mais, ganha espaço a utilização de métodos técnicos, jurídicos e econômicos que possibilitem enfrentar temas jurídicos de maneira a obter, efetivamente, melhor bem-estar possível, com menor prejuízo. Por meio da Análise Econômica do Direito, os juízes e legisladores devem estabelecer normas jurídicas que induzam um comportamento eficiente (economicamente ou não), embora a eficiência seja apenas mais um valor a ser perseguido pelo Direito, mas não o único ou o mais importante.

A Lei do Bem regula uma política pública de concessão de incentivos fiscais para inovação tecnológica em P\&D e para atividades correlatas, que permite reduzir o custo e o risco associados a esse tipo de inovação nas empresas. O estudo traz dados otimistas de aumento de investimentos em P\&D por parte das empresas beneficiadas, bem como de incremento no número de empresas que utilizam a Lei do Bem. Esta lei repercute a tendência internacional da inovação aberta ao conceder dentre os incentivos o da renúncia fiscal para os gastos relacionados às atividades de cooperação tecnológica universidade-empresa.

Nesse diapasão, o estudo, ao utilizar a metodologia de pesquisa exploratória, observou a aplicabilidade da Teoria da Agência para as cooperações tecnológicas havidas entre universidades e empresas, por ser capaz de auxiliar no aperfeiçoamento da gestão dessas interações, devido à existência de conflito de interesses entre as partes envolvidas. O conflito decorre do acesso diferenciado que agente (universidade) e principal (empresa) têm às informações: a universidade (pesquisadores), por estar atuando diretamente no processo, possui um grau mais aprofundado de conhecimento sobre o andamento das pesquisas. Na realidade, ambas as partes da relação de cooperação tecnológica são maximizadoras de utilidade, sendo assim, é de se esperar que a universidade nem sempre atue de acordo com os interesses da empresa.

Então, percebe-se que a adequação da Teoria de Agência ao ambiente das pesquisas tecnológicas pela cooperação entre universidades e empresas pode ser visualizada na própria atuação dos participantes dessas cooperações. No caso da cooperação tecnológica, pela Teoria da Agência, a empresa (principal) deve delegar à universidade (agente) alguma autoridade para a tomada de decisão. Conceitualmente, a cooperaçao tecnológica possibilita a repartição de custos e riscos e a ampliação da competitividade e o conhecimento científico de uma nação. Entretanto, a pesquisa verificou que, para os contratos de cooperação beneficiados, o legislador impôs que o poder para tomada de decisões é da empresa. Dessa forma, a Lei do Bem restringe o poder de livre negociação das cláusulas contratuais pelas partes da cooperação tecnológica.

A partir do levantamento bibliográfico realizado, verificou-se que essas condições estabelecidas pelo legislador são, muitas vezes, menos eficientes se comparadas com condições que decorrem de acordos entre as pessoas. Nessa ordem de idéias, esta investigação alcança o objetivo perseguido, pois, diante da identificação das condições impostas pelo legislador para conceder benefícios fiscais para cooperação tecnológica, verifica-se que a Lei do Bem não possui um sistema de incentivos suficientes para resolver os conflitos de agência existentes nas cooperações tecnológicas entre universidades e empresas.

Revista do Direito [ISSN 1982-9957]. Santa Cruz do Sul, v. 3, n. 56, p. 3-16, set/dez. 2018. https://online.unisc.br/seer/index.php/direito/index 
Nesse diapasão, as contribuições da Teoria da Agência ampliam o debate acerca das cooperações tecnológicas, abrindo novos caminhos para o aperfeiçoamento da Lei do Bem, haja vista a necessidade de melhoria no desenho da cooperação tecnológica universidade-empresa em relação aos conflitos e custos. Nessa perspectiva, propõe-se que a Lei do Bem seja repensada para criar uma estrutura de recompensas à universidade como meio de tornar mais eficientes os contratos de cooperação tecnológica. Isso fornecerá maior incentivo ao trabalho dos pesquisadores, possibilitando reduzir ou solucionar os conflitos de agência existentes na cooperação tecnológica universidadeempresa.

\section{REFERÊNCIAS}

AVELLAR, Ana Paula Macedo de; BOTELHO, Marisa dos Reis Azevedo. Efeitos das políticas de inovação nos gastos com atividades inovativas das pequenas empresas brasileiras. Estudos Econômicos. São Paulo, v. 46, n. 3, p. 609-642, set., 2016.

BRASIL. Constituição (1988). Constituição da República Federativa do Brasil. Brasília, DF, Senado, 1988. Disponível em:

<https://www.planalto.gov.br/ccivil_03/constituicao/constituicao.htm>. Acesso em: 04 fev. 2018.

BRASIL. Lei no. 10.973 - Lei de Inovação, de 2 de dezembro de 2004. Diário Oficial da União, Poder Legislativo. Brasília, DF, 3 dez. 2004. Seção 1, p. 2.

BRASIL. Lei oํ 11.196 - Lei do Bem, de 21 de novembro de 2005. Diário Oficial da União, Poder Legislativo. Brasília, DF, 22 nov. 2005. Seção 1, p. 1.

BRASIL. Lei no 13.243 - Código de Ciência, Tecnologia e Inovação, de 11 de janeiro de 2016. Diário Oficial da União, Poder Legislativo. Brasília, DF, 12 jan. 2016. Seção 1, p. 1.

BRASIL. Instrução Normativa RFB no 1.187, de 29 de agosto de 2011. Diário Oficial da União, Poder Executivo. Brasília, DF, 30 ago. 2011, p. 19.

BRASIL. Ministério da Ciência, Tecnologia, Inovações e Comunicações - MCTIC. Relatório anual de incentivos fiscais. Brasília: 2014. Disponível em:

<http://www.mctic.gov.br/mctic/export/sites/institucional/tecnologia/incentivo desenvolvimento/lei bem /arquivos/Relatorio-Anual-Lei-11196-05-Ano-Base-2014.pdf>. Acesso em: 04 fev. 2018.

CAMINHA, Uinie; LIMA, Juliana Cardoso. Contrato incompleto: uma perspectiva entre direito e economia para contratos de longo termo. Revista Direito GV, São Paulo, v. 10, n. 1, p. 155-200, janjun., 2014.

CHESBROUGH, Henry. Open Innovation: The New Imperative for Creating and Profiting from Technology. Boston: Harvard Business School Press, 2003.

COASE, Ronald $\mathrm{H}$. The problem of social cost. The Journal of Law and Economics, v. 3, p. 1-44, Oct. 1960. Disponível em:

<http://www2.econ.iastate.edu/classes/tsc220/hallam/Coase.pdf> Acesso em: 04 fev. 2018.

COOTER, Robert; ULEN, Thomas. Direito \& economia. Tradução de Luis Marcos Sander e Francisco Araújo da Costa. 5. ed. Porto Alegre: Bookman, 2010.

DINIZ, Francisco. Crescimento e desenvolvimento econômico: modelos e agentes do processo. 2. ed. São Paulo: Edições Sílabo, 2010. 
HALL, Bronwyn H. The Financing of Research and Development. Oxford Review of Economic Policy, 2002.

JENSEN, Michael C. Self-interest, Altruism, Interest and Agency-Theory. Journal of Applied Corporate Finance, n. 7, 1994, pp. 40-45.

JENSEN, Michael; MECKLING, H. William. Theory of the firm: managerial behavior, agency costs and ownership structure. Journal of Financial Economics, v. 3, n. 4, p. 305-360, 1976.

ORGANIZAÇÃO PARA A COOPERAÇÃO E DESENVOLVIMENTO ECONÓMICO - OCDE. Manual de Frascati: metodologia proposta para definição da pesquisa e desenvolvimento experimental. Coimbra: F-Iniciativas, 2013.

PIMENTA, Eduardo Goulart. Recuperação de empresas: um estudo sistematizado da nova lei de falências. São Paulo: IOB Thompson, 2006.

PORTO, Antônio Maristrello. Análise Econômica do Direito (AED). 2013. Disponível em: <http://direitorio.fgv.br/sites/direitorio.fgv.br/files/u100/analise_economica_do_direito_20132.pdf> Acesso em: 04 fev. 2018.

POSNER, Richard A. Economic analysis of law. 7. ed. New York: Aspen, 2007.

PRATT, John .W.; ZECKHAUSER, Richard J. Principals and agents: an overview. In: PRATT, John W.; ZECKHAUSER, Richard J. Principals and agents: the structure of business. Boston: Harvard Business School Press, 1985. p.1-35. Disponível em:

<https://www.researchgate.net/publication/247249967_Principals_and_Agents_The_Structure_of_Bus iness> Acesso em: 04 fev. 2018.

RIBEIRO, Márcia Carla Pereira; GALESKI, Irineu Júnior. Teoria Geral dos Contratos: contratos empresariais e análise econômica. São Paulo: Elsevier, 2009.

SEGATTO-MENDES, Andréa Paula; MENDES, Nathan. Cooperação tecnológica universidadeempresa para eficiência energética: um estudo de caso. Revista de Administração Contemporânea, Rio de Janeiro, v. 10, p. 53-75, 2006.

SEGATTO-MENDES, Andréa Paula; ROCHA, Carvalho Keyler. Contribuições da teoria de agência ao estudo dos processos de cooperação tecnológica universidade-empresa. Revista de Administração (USP), São Paulo, v. 40, n. 2, p. 172-183, 2005.

VOSGERAU, Douglas; GONÇALVES, Oksandro. A extrafiscalidade como política pública de intervenção do estado na economia e desenvolvimento: o ICMS ecológico e o IPI de veículos automotores. Ciências Sociais Aplicadas em Revista, Paraná, v. 13, n. 24, p. 207-221, 2013.

\section{COMO CITAR ESSE DOCUMENTO:}

CAMINHA, Uinie; MEMORIA, Caroline Viriato. A política pública de inovação tecnológica e a cooperação universidade-empresa: revisitando a teoria da agência. Revista do Direito, Santa Cruz do Sul, v. 3, n. 56, jan. 2019. ISSN 1982-9957. Disponível em: <https://online.unisc.br/seer/index.php/direito/article/view/11626>. Acesso em: doi:https://doi.org/10.17058/rdunisc.v3i56.11626. 